\title{
EL RECURSO EXTRAORDINARIO. LA CUESTIONADA INNOVACIÓN DEL PROYECTO DE LEY DEL NUEVO Código Procesal Civil Chileno*
}

\author{
Ignacio Alejandro Avendaño Leyton"***
}

\begin{abstract}
RESUMEN
El presente artículo trata sobre la regulación del Recurso Extraordinario en el Proyecto de Ley del nuevo Código Procesal Civil chileno y las diversas opiniones que se han generado tanto en la doctrina nacional como internacional respecto de su implementación y el rol que ocuparía la Excelentísima Corte Suprema en su conocimiento.
\end{abstract}

Palabras clave: Recurso extraordinario, Código Procesal Civil.

\begin{abstract}
This article deals with the regulation of the extraordinary appeal on Bill Chilean Civil Procedure Code and the various opinions that have been generated in both national and international doctrine for its implementation and the role that occupy the Supreme Court in their knowledge.
\end{abstract}

Key Words: Extraordinary appeal, Civil Procedure Code.

* Parte del presente artículo fue publicado en una columna en el sitio internet www.lexweb.cl, en la cual el autor permanentemente realiza publicaciones.

*: Licenciado en Ciencias Jurídicas y Sociales de la Universidad Central de Chile, en donde fue alumno ayudante de la Cátedra de Derecho Procesal en los años 2007 y 2008. Además, durante su historial universitario, fue distinguido durante cuatro años consecutivos con la Beca al Mérito Académico en reconocimiento a su rendimiento obtenido en los respectivos años lectivos del ciclo de pregrado. Actualmente, se dedica al ejercicio libre de la profesión y fue elegido por concurso público como profesor ayudante de la cátedra de Derecho Procesal en la Universidad Central de Chile. Además, es columnista permanente del área de Derecho Procesal del sitio de internet www.lexweb.cl. 
El Proyecto de Ley del nuevo Código Procesal Civil chileno (en adelante PdCPC), actualmente en tramitación, trae consigo un sinnúmero de novedades en el ámbito procedimental, entre otras, la oralidad del proceso, impulso procesal de oficio, el Oficial de Ejecución y el denominado Recurso Extraordinario, este último se encuentra reglado en Libro III sobre "Los Recursos Procesales", Título V, artículos 405 y siguientes del PdCPC, no obstante, éste recurso que se intenta implementar en el ordenamiento jurídico chileno no ha estado exento de innumerables críticas, por lo que trataremos de explicar someramente su regulación, ventajas y detracciones, para al final dar una opinión objetiva sobre este trascendental tema.

\section{REgulación}

Para comenzar quisiéramos señalar que, según el mensaje del PdCPC, este recurso

“constituye una de las innovaciones más importantes que contempla el Código" reemplazando "el actual recurso de casación en el fondo, por un recurso extraordinario a través del cual se fortalece el rol del Corte Suprema como máximo tribunal de la República encargado de preservar los derechos fundamentales y de dar coherencia y unidad a los criterios de decisión de los tribunales del país.

La Corte podrá avocarse al conocimiento de un asunto siempre que concurra un interés general que haga necesaria su intervención y ello con base en un sistema amplio de tipificación de causales que justifiquen ese interés general". ${ }^{1}$

Tal como señala el mensaje recién transcrito, se trata de un recurso excepcional y de competencia exclusiva y excluyente de la Excma. Corte Suprema. El objeto del recurso es que el agraviado por una sentencia pueda ocurrir ante el Máximo Tribunal del país para solicitarle que se avoque al conocimiento de un asunto por estimarse afectado un interés general (artículo 405 del PdCPC).

Las resoluciones impugnables a través del recurso extraordinario serán aquellas sentencias definitivas e interlocutorias, inapelables, que pongan término al juicio o hagan imposible su continuación, dictadas por Cortes de Apelaciones (artículo 406). Su plazo de su interposición es dentro de los quince días siguientes a la notificación de la sentencia al recurrente por la Corte de Apelaciones respectiva, debiendo el recurso interponerse directamente ante la Excma. Corte Suprema (artículo 407).

$1 \quad$ Vid. Mensaje enviado por S.E. el Presidente de la República de Chile, don Sebastián Piñera Echeñique, $\mathrm{N}^{\circ}$ 004-360 enviado al Congreso Nacional el día 12 de marzo del año 2012, disponible en: http://www.camara.cl/pley/pley_detalle.aspx?prmID=8596\&prmBL=8197-07 [Consultado el 08 abril 2013], p. 23. 
Los requisitos formales para su interposición son los siguientes: 1) debe presentarse por escrito, 2) debe expresarse el agravio, 3) debe fundamentarse las razones por las cuales concurre el interés general que justifica la intervención de la Corte Suprema y, 4) debe señalarse las peticiones concretas que se someten a la consideración de la Corte Suprema para subsanar el agravio invocado (artículo 408).

Ahora bien, "podrá" estimarse que concurre un interés general para avocarse al conocimiento de un asunto: a) Cuando se hubiere infringido en forma esencial, en la sentencia o en el procedimiento del cual ella emanare, un derecho o garantía fundamental contemplado en la Constitución Política de la República o en los tratados internacionales ratificados por Chile y que se encuentren vigentes y; b) En caso que considere pertinente fijar, uniformar, aclarar o modificar, una doctrina jurisprudencial (artículo 409).

No obstante, la Excma. Corte determinará avocarse al conocimiento del asunto cuando la mayoría de los miembros de la sala respectiva (tres ministros) estime que concurre un interés general que haga necesaria su intervención.

En cuanto a la admisibilidad del recurso, la Corte Suprema admitirá para su conocimiento sólo aquellos recursos que, cumpliendo con los requisitos formales, revistan interés general (certiorari negativo). Por su parte, si la Corte Suprema declara inadmisible el recurso por estimar que no se cumple con los requisitos formales, deberá señalarlo fundadamente en la resolución que pronuncie al respecto, otorgando al recurrente el plazo de cinco días para subsanar dichos defectos.

En este sentido, el sistema propuesto en el PdCPC no considera lo que en doctrina se denomina certiorari positivo, y que consiste en que el Máximo Tribunal, también en el plano de su discrecionalidad, podría excepcionalmente, en lugar de rechazar el recurso, admitirlo aun cuando existiera algún obstáculo formal para acceder a ese Tribunal, si el caso presenta gravedad o trascendencia.

Eso sí, previo a resolver sobre la admisibilidad del recurso, la Corte Suprema podrá dar traslado al recurrido, para que en el plazo de diez días haga valer las razones por las cuales, en su concepto, no se justifica que la Corte Suprema se avoque al conocimiento del asunto.

La Excma. Corte deberá pronunciarse sobre la admisibilidad dentro de los treinta días siguientes a su ingreso. Declarada la admisibilidad del recurso, dicha resolución deberá ser notificada, electrónicamente, al recurrido que no hubiere comparecido previamente de acuerdo a lo señalado en el párrafo anterior (artículo 410).

En relación a los efectos del recurso, su interposición no suspende la ejecución ni los efectos de la sentencia recurrida. Con todo, la Corte Suprema podrá decretar orden de no innovar de oficio o a petición de parte, cuando el cumplimiento o los efectos de la sentencia recurrida hicieren imposible cumplir la que se dictare si se acogiere el recurso o existieren razones fundadas para ello, las que expresará 
circunstanciadamente en su resolución. En dicha resolución deberá determinar el alcance de la orden de no innovar.

Los fundamentos de las resoluciones que se dicten de conformidad a lo señalado en el párrafo anterior no constituirán causal de inhabilidad (artículo 411).

En cuanto al fallo del recurso, la Corte Suprema actuando en Sala o en Pleno según el caso, deberá fallar el recurso dentro de los veinte días siguientes a la fecha en que hubiere terminado la audiencia de vista. En la sentencia la Corte Suprema deberá exponer los fundamentos que se tuvieron presente para declarar la admisibilidad del recurso y si se acogiere, la forma en que se ha verificado la infracción esencial del derecho fundamental o la manera en la cual deberá ser interpretada o aplicada una determinada norma o principio jurídico y concluirá declarando la confirmación, modificación, revocación o invalidación de la sentencia recurrida y del procedimiento del cual emanare en su caso.

Si la Corte Suprema al acoger el recurso extraordinario anulare la sentencia recurrida, dictará sentencia de reemplazo. Si anulare el juicio en el cual se hubiere pronunciado, determinará el estado en que hubiere de quedar el procedimiento y ordenará la comunicación al tribunal no inhabilitado que correspondiere, para que éste disponga la realización de un nuevo juicio (artículo 413).

La resolución que fallare un recurso extraordinario no será susceptible de recurso alguno, sin perjuicio de lo previsto en el artículo 211 del PdCPC (recurso, aclaración, rectificación o enmienda).

Excepcionalmente, si se demostrare que la sentencia se ha dictado contradice otra pronunciada por la misma Sala especializada, pero sin que en el fallo se hubiere dejado constancia de haberse modificado la doctrina anterior, el recurrente podrá dentro del plazo de quince días solicitar al Pleno que se anule la sentencia y para que se proceda a una nueva audiencia por una sala no inhabilitada. Esta solicitud de nulidad será resuelta por el Pleno sin audiencia pública de vista de la causa (artículo 414).

Todas las sentencias que fallen un recurso extraordinario deberán ser publicadas en la página Web del Poder Judicial de Chile², conteniendo especialmente un extracto de la doctrina jurisprudencial que se haya establecido con motivo del fallo.

La publicación deberá además señalar nominativamente qué ministros fueron los redactores de los votos de mayoría, de minoría y quienes concurrieron a la vista y acuerdo (artículo 415). En la cuenta anual del Presidente de la Corte Suprema deberá efectuarse una breve reseña de los recursos extraordinarios acogidos durante el año anterior (artículo 416).

$2 \quad$ www.poderjudicial.cl o www.pjud.cl 
En fin, ya aclarado cuales son los requisitos, causales, tramitación y fallo del recurso extraordinario, nos corresponde hacernos cargo de las ventajas y críticas que se han formulado respecto de éste.

\section{EL WRIT OF CERTIORARI}

Tal como pudimos verificar, en el PdCPC se introducen ciertos criterios de discrecionalidad en la admisibilidad del recurso extraordinario, correspondiendo a la sala respectiva de la Corte Suprema decidir, soberanamente, si las razones invocadas por el justiciable califican o no con ser de interés general y, por ende, si amerita la Excma. Corte avocarse o no al conocimiento del asunto.

Esta potestad discrecional que se le concede a nuestro Máximo Tribunal se conoce en el derecho comparado como writ of certiorari, tratando de aproximar la labor de la Corte con la de su par de Estados Unidos reservando su intervención para un limitado número de casos en que estuvieran comprometidas cuestiones de gran repercusión social.

Esta institución proviene directamente del common law y consiste en un mandato $\mathrm{u}$ orden (writ) emitido por una Corte o Tribunal de Alzada a su inferior jerárquico, ordenándole a este último, certificar lo actuado y remitirle el expediente a fin de que, el tribunal que la expide, pueda inspeccionar el procedimiento seguido $y$, determinar si existen o no irregularidades en el mismo.

En este sentido, el profesor Barrancos y Vedia señala que "lo que en el derecho inglés y de los Estados Unidos se llama certiorari, consiste en un procedimiento de revisión de actuaciones tramitadas y de resoluciones tomadas en instancias inferiores, comparable a lo que entre nosotros se llama avocación". ${ }^{3}$

Este procedimiento de "avocación" que es el writ of certiorari norteamericano, tiene un amplísimo alcance que lo hace admisible en todas las etapas e instancias de cualquier clase de juicios de modo tal que su admisión no sólo es atribución que competa a la Suprema Corte, sino también a las "Cámaras Federales de Apelación" (Courts of Appeals) y, desde luego, también a la "justicia local" o tribunales estaduales.

Denominado en estos últimos casos como certification, el writ of certiorari también es utilizado al modo de una "consulta", por la cual los tribunales inferiores pueden requerir a la Suprema Corte, su opinión previa sobre las cuestiones de hecho o derecho del caso que deben resolver. ${ }^{4}$

Sólo parcialmente limitado cuando es interpuesto ante la Suprema Corte, ésta se encuentra legislativamente facultada, a su "discrecional" admisión o no, si al menos

\footnotetext{
3 BARRANCOS y VEDIA, Fernando, Recurso extraordinario y gravedad institucional, Buenos Aires, Editorial Abeledo Perrot, $2^{\text {a }}$ edición, 1991, p. 134

4. Ibídem, p. 138.
} 
4 de sus 9 jueces votan por oír el caso, tal como así lo establece la actual "Regla 17" de la Suprema Corte norteamericana que bajo el título de "Consideraciones que rigen la revisión por certiorari" prevé que: "La revisión por writ of certiorari no es una cuestión de derecho sino de discrecionalidad judicial, y será admitida sólo cuando existan especiales e importantes razones para ello...". ${ }^{5}$

En este entendido, la Suprema Corte de Estados Unidos, conoce sólo el 1\% de las peticiones de certioriari que se le presentan anualmente. El criterio de este último tribunal para aceptar la revisión de sentencias se basa -dado su carácter de Corte constitucional- fundamentalmente en la relevancia de la pregunta constitucional que el caso plantea (además de otras situaciones propias del sistema de gobierno federal). El criterio de selección del PdCPC es el "interés general” que el caso presente, expresado por tres de los miembros de la Corte (la Corte Suprema de Estados Unidos exige cuatro de nueve miembros), sin necesidad de fundamentación.

Más cerca, en la República Argentina, se implantó esta misma técnica con la finalidad de disminuir el importante caudal de expedientes que ingresaban a la Corte Suprema de Justicia de la Nación (en adelante CSJN), por la vía del recurso extraordinario federal por arbitrariedad de sentencia, por lo que la Corte acudió a la herramienta del certiorari, incorporada por la Ley $\mathrm{N}^{\circ} 23.774$ de 1990, a través de la cual se persigue reservarla sólo para asuntos significativos. De conformidad a la ley citada, la Corte, según su sana discreción y con la sola invocación de esa norma, puede desestimar el recurso extraordinario o la queja por falta de agravio federal suficiente o cuando las cuestiones planteadas resultaren insustanciales o carentes de trascendencia. No obstante, éste certiorari ha sido muy criticado por la discrecionalidad atribuida a la CSJN para abrir o cerrar su competencia extraordinaria, derivada de la amplitud de las causales y de la inexigibilidad de fundamentación de la correspondiente resolución, con seria afectación al derecho de defensa. Principalmente se sostuvo que el empleo de la herramienta, en las condiciones reguladas por la ley 23.774, puede dar como resultado un tratamiento desigual a dos juicios semejantes. Este mecanismo ha generado una muy fuerte desconfianza en los litigantes, puesto que no se saben cuáles son las causales del rechazo, apartándose así de la exigencia constitucional referida a la motivación suficiente de las resoluciones judiciales y que en numerosísimos casos, su inobservancia, fue sancionada por la misma CSJN ${ }^{6}$.

Por su parte, al margen de los cuestionamientos acerca de la discrecionalidad del certiorari argentino, lo concreto es que a partir de su incorporación -en la prácticano ha disminuido la congestión de expedientes. En efecto, se comparó el número de

Ibídem, p.136.

6 SBDAR, Claudia Beatriz, "Presente y futuro del recurso extraordinario federal. El rol de la Corte Suprema de la Nación”, Revista Iberoamericana de Derecho Procesal Constitucional, núm. 10, julio-diciembre 2008, México DF, pp. 217-248. 
fallos que emitía el Tribunal antes de la entrada en vigencia de la ley y algunas de las cifras correspondientes a los últimos años, se observó que lejos de registrarse una baja, ellos siguieron en aumento. A modo de ejemplo, en 1989 el Tribunal resolvió anualmente entre 5.000 y 6.000 casos, en tanto que en 2000 fueron 15.454, 6.578 no previsionales y 8.876 previsionales y en $2001,15.263,6.463$ no previsionales y 8.440 previsionales. De modo que está funcionando un instrumento, fuertemente criticado por no acercar a los abogados pautas claras acerca de qué cuestiones pueden o no ingresar a la Corte, que además no ha producido el efecto pretendido de disminución del caudal de expedientes que ingresan a la Corte. ${ }^{7}$

\section{Ventajas}

Según el informe del Centro de Estudios e Investigación Libertad y Desarrollo de Chile ${ }^{8}$, uno de los aspectos más relevantes del PdCPC dice relación con "racionalizar" la utilización de la Corte Suprema, ya que, según éste estudio, la Corte se ha transformado en una verdadera instancia, perdiendo toda posibilidad de ser realmente un Tribunal de Casación que tiene por objeto uniformar el derecho interno.

En ese sentido, mediante la utilización de cifras cuantitativas éste estudio demuestra la evolución de los ingresos de casos a la Corte Suprema que ha sido creciente año a año, desde el año 2006. Destacando el crecimiento experimentado durante 2008, donde el total de ingresos aumentó en un 19,6\% respecto al año anterior, y el crecimiento experimentado durante 2011, con una variación de 24,7\% respecto a 2010. Respecto al total de fallos anuales de la Corte Suprema, se ve que la tendencia es creciente a partir del 2007, y destaca el año 2011 donde el total de fallos experimenta un crecimiento de $34,5 \%$ respecto a 2010 , superando incluso el total de ingresos del mismo año y disminuyendo por ende el total de causas pendientes en un 19,2\%. A pesar de la disminución de causas pendientes durante el último año, el aumento neto que se ha producido en el número de causas pendientes respecto al período 2006-2008, es preocupante. Aumentos en los ingresos de causas debiesen traducirse en incremento de términos en la misma proporción de fallos, puesto que el stock de causas pendientes genera ineficiencias en el sistema. Bajo esta perspectiva se destaca la labor realizada durante 2011, donde el total de fallos excedió por 990 causas al total de ingresos.

En cuanto a la composición de los ingresos, éste estudio demuestra que la casación de fondo civil constituye el principal asunto, siendo un $37 \%$ del total de

Ibídem, p. 237.

Vid. Informe de Justicia $\mathrm{N}^{\circ}$ 9, de abril 2012, sobre "Reforma a la Justicia Civil y Comercial en Chile", disponible en: http://www.lyd.com/wp-content/files_mf/sij9reformaalajusticiacivilycomercialenchileeclaroyjfgarciaabril2012.pdf [Consultado el 07 enero de 2013], p.23. 
los ingresos, seguido por las apelaciones de protección que son un $26 \%$ del total de los ingresos de 2010 (esto último vinculado al boom en litigación en los casos de afiliados contra sus ISAPRE por aumentos en los planes en la salud fruto de la controversial jurisprudencia del Tribunal Constitucional de Chile en esa materia).

En relación a la composición de las causas falladas por la Corte Suprema de Chile en 2010, se determinó que las principales materias la constituyen la casación de fondo civil, con un $38 \%$ del total de las principales causas falladas y las apelaciones de protección con un $25 \%$. Los siguen las casaciones de forma y fondo civil con un $11 \%$ y los exhortos con un $10 \%$.

Por último, respecto a las causas pendientes, la composición varía bastante en relación a ingresos y fallos. Destacan las casaciones de fondo civil con un 58\%, seguido por las casaciones de fondo y forma civil que constituyen un $18 \%$ del total de las principales causas pendientes. Las apelaciones de protección pasan a ser solo un $10 \%$ de las principales causas pendientes y los exhortos, un $8 \%$. De esta forma es posible concluir que la Corte Suprema tiende a fallar en menor proporción las casaciones (tanto de fondo civil como de forma y fondo civil), las que aumentaron en un $4,8 \%$ respecto al año 2009 , y que las apelaciones de protección, a pesar de que en términos proporcionales tienden a quedar en menor proporción como pendientes, en 2010 sí presentaron un aumento significativo respecto a 2009, con una variación de 44\%, equivalente a 124 causas más en stock que en 2009.

Ahora bien, respecto al rol de la Corte Suprema y al impacto que tiene el PdCPC, éste realiza una profunda reforma al sistema recursivo actual, proponiendo, según el estudio, un sistema simple, eficiente y equilibrado. Es por ello que el PdCPC propone, correctamente a juicio del Centro de Estudios, restringir al máximo el número de recursos que serán conocidos por la Corte Suprema, por lo que propone eliminar el recurso de casación en la forma (cuyas causales de nulidad se funden en la regulación del nuevo recurso de apelación, que asume la condición de recurso de nulidad), y reemplazar el actual recurso de casación en el fondo, por un recurso extraordinario mediante, básicamente, un mecanismo de libre selección de casos por parte de las salas, donde la Corte podrá avocarse al conocimiento del asunto, siempre que concurra un interés general que haga necesaria su intervención, y con una tipificación de causales que justifiquen dicho interés general ${ }^{9}$.

Por su parte, los profesores Jordi Delgado y L. Iván Díaz, sostienen que existen varias ventajas de la unificación de jurisprudencia pretendida por el recurso extraordinario a partir de su configuración legislativa. Entre tales ventajas destacan las siguientes: a) asegura la igualdad en la aplicación de la ley; b) incrementa la seguridad jurídica; c) disminuye la litigiosidad; d) facilita la tarea interpretativa de los tribunales; e) precisa los costos que tienen ciertas decisiones jurídicas; f) incrementa la confianza en el sistema judicial; g) fortalece la legitimidad del

\footnotetext{
Ibidem, p. 28.
} 
Poder Judicial; y h) disminuye la intervención de elementos extrajurídicos en las decisiones judiciales. Las ventajas expresadas en las letras c), d) y e) responden a una perspectiva de análisis económico del Derecho. Los tres últimos, por su parte, pueden ser genéricamente denominados objetivos políticos. ${ }^{10}$

\section{Críticas}

Principales cuestionamientos:

4.1 Tal como se señaló supra, el recurso extraordinario ha sido objeto de varias críticas, entre estas, aquellas relativas a la discrecionalidad de la cual estaría investida la Excma. Corte Suprema para efectos de avocarse al conocimiento de un determinado asunto. En este sentido, el profesor Mario Rojas Sepúlveda sostiene que el recurso extraordinario propuesto, deja al litigante al mero arbitrio de las subjetividades de los ministros de la Corte Suprema, que puedan examinar, o no, su impugnación, en función de una hipótesis enteramente indeterminada (si reviste interés público a juicio de a lo menos tres ministros e injusticia notoria), agregando, que la modernidad -artificiosa e irreflexiva- no siempre aporta progreso. ${ }^{11}$

4.2 Por otro lado, las críticas también han surgido de parte de profesores de derecho civil, los que han cuestionado el tratamiento que se da a esta figura, por cuanto, según ellos, el recurso extraordinario viene a repercutir sobre la regla del artículo $3^{\circ}$ del Código Civil, que prescribe que sólo corresponde a la ley realizar interpretaciones con efectos vinculantes generales, y aquélla contenida en la sentencia sólo tiene efectos vinculantes para el caso particular.

Agregan que la manera cómo ha sido concebido el recurso extraordinario en el PdCPC no soluciona, sino que agrava el estado de cosas. Y lo anterior, puede ser un problema transcendental, no sólo para las instituciones civiles, sino también para el Estado de Derecho.

Algunos de los fundamentos que dan respecto de esta conclusión, son los siguientes:

El recurso es completamente "excepcional", pues su interposición se justifica cuando existe violación del "interés general", definido de manera muy restrictiva: infracción de derechos constituciones y necesidad de formar y uniformar doctrina.

10 DELGADO, Jordi y DÍAZ, L. Iván, "La Unificación de Jurisprudencia pretendida por el Recurso Extraordinario. Ventajas y Problemas", Revista de Derecho Universidad Católica del Norte, sección Ensayos, Año 18 - N² 2. 2011, Coquimbo, Chile, pp. 275-304.

11 ROJAS SEPÚlVEDA, Mario, "El rol de la Corte Suprema en el proyecto del nuevo Código Procesal Civil”, Revista Actualidad Jurídica, N 22 - julio 2010, Universidad del Desarrollo, Santiago de Chile, p. 353. 
Sobre la primera causal de configuración del interés general, señalan que la alegación sobre la base de derechos constitucionales ahonda lo que se denomina vulgarización del derecho civil. La Constitución es, por cierto, la norma suprema. Pero ella representa un marco abierto de derechos o principios en conflicto, cuya aplicación puede conducir a una multiplicidad de soluciones, precisamente, por su carácter abierto. Es la legislación civil la que viene a concretar esa regulación, la que enriquece con criterios y reglas específicas, otorgándole contenido a los derechos civiles, y proporcionando soluciones claras y, la mayor parte del tiempo, unívocas a situaciones concretas.

Sobre la segunda causal de configuración del interés general, ellos se preguntan:

¿Cómo no va a ser necesario siemprefijar y uniformar doctrinas jurisprudenciales? Siempre lo ha sido, es la misión misma de una Corte Suprema. Por lo demás, esta necesidad de fijar y uniformar doctrinas jurisprudenciales responde a la garantía constitucional de la igualdad ante la ley, pues no es conforme a dicha garantía que la ley sea aplicada de manera diversa a los ciudadanos.

Asimismo cuestionan que el recurso ya no considera la causal de infracción de ley que influya substancialmente en lo dispositivo del fallo. No se puede alegar que se infringió el Código Civil para exigir la intervención de la Corte Suprema, sino que todo se reconduce a una elemental y estandarizada discusión constitucional.

Critican, además, que la redacción deja la impresión de que se quiere que la Corte Suprema se pronuncie en muy contadas ocasiones (completamente excepcionales) y que, en tales ocasiones, prácticamente dicte normas con efectos generales, invadiendo las competencias de otro órgano del Estado y, por ello, podría ser objetable desde la perspectiva de la Constitución.

Es más, señalan que en las contadas ocasiones en que podrá (o más bien, querrá) intervenir la Excma. Corte, se la obliga a convertirse en una "jurisdicción constitucional", pues sólo podrá razonar en términos de "derechos fundamentales" y no podrá razonar y velar por el respeto de la ley civil. La jurisdicción constitucional, luego de la reforma del año 2005, está entregada por completo al Tribunal Constitucional, quien realiza el control preventivo y ex-post, por lo que dotar a la Corte Suprema de tales competencias requiere de una reforma a la Carta Fundamental.

Según ellos, esto implica, que en la práctica y entre otros efectos, una derogación tácita del artículo $3^{\circ}$ del Código civil. Artículo que más que una norma de Derecho Civil, es una norma fundamental de nuestro sistema de fuentes del Derecho.

Finalizan señalando que al estar redactados los textos referentes al recurso extraordinario de forma tal que lo vuelven sumamente excepcional, es discutible entonces que el mismo permita cumplir la función uniformadora de jurisprudencia de la Corte Suprema que se pretende con su creación. ${ }^{12}$

12 Vid. "Comentarios al Proyecto de nuevo Código Procesal Civil", Departamento Derecho Procesal Universidad Diego Portales, 2010, Santiago de Chile, disponible en: http://www.re- 
4.3. Otro cuestionamiento se ha instalado respecto de la necesidad de reducir el número de asuntos a decidir, sin embargo, para ello hay que tener presente que durante el año 2011 se ingresó a trámite un total de 3.477 recursos de casación en el fondo, de los cuales 2.784 corresponden a ingresos civiles; 126, criminales; 518, de familia; más 28 causas de cobranza y 23 ingresos de Reforma Laboral. Si consideramos un total que excede las 12.300 causas totales ingresadas durante el año 2011 al Máximo Tribunal, no cabe duda que el mecanismo propuesto generará resultados escuálidos, ya que la reforma no se hace cargo de las casi tres cuartas partes que componen el volumen general de ingresos. ${ }^{13}$

4.4. Por su parte, nuestro Tribunal Constitucional chileno en la causa rol 2005 del año 1995, tuvo la oportunidad de pronunciarse sobre el certiorari con ocasión de la reforma del año 1995 introducida finalmente por la Ley $\mathrm{N}^{\circ}$ 19.374, en relación a las precisiones en cuanto a la casación y fines de todo proceso judicial.

Así, en su razonamiento Noveno se sostiene que

“...El conflicto es una realidad históricamente demostrada, actualmente cada vez más aguda, y se genera precisamente cuando un sujeto con su actuación u omisión infringe una ley. Su solución a través del proceso cumple dos objetivos: a. La satisfacción del interés subjetivo de los sujetos en conflicto. b. La actuación del derecho objetivo para mantener la exacta observancia de la ley. Esta debe ser acatada por las partes del proceso y por los jueces de la instancia. Para controlar a estos últimos se han establecido los recursos de casación y de queja“.

El motivo siguiente se inicia con una muy contundente afirmación, cual es "(que,) los antecedentes más remotos de la casación de fondo la configuran como una de las máximas expresiones de la garantía del estado de derecho y de la igualdad ante la ley".

Es como si entre debido proceso, igualdad ante la ley y recurso de casación hubiera una ligazón indisoluble. Prosigue la sentencia señalando el origen y desarrollo histórico de esta institución, para aseverar de modo categórico lo siguiente:

“ $13^{\circ}$. Que, debe tenerse especialmente en cuenta lo dispuesto en el artículo 74 de la Constitución Política, que le otorga un mandato al legislador para dictar la ley orgánica constitucional que determine la organización y atribuciones de los tribunales que fueren necesarios para la pronta y cumplida administración de justicia en todo el territorio de la República. En este orden de ideas, resulta

formasprocesales.udp.cl/wp-content/uploads/2010/09/observacionesdelDepartamentodeDerecho.pdf [Consultado el 07 de enero 2013], p. 7.

13 Vid. "Reforma Procesal Civil, recursos legales y atribuciones de la Corte Suprema", Ideas \& Propuestas $\mathrm{N}^{\circ}$ 112, 31 de octubre de 2012, Fundación Jaime Guzmán, disponible en: http:// www.jaimeguzman.cl/wp-content/uploads/2012/10/iyp_1121.pdf, [Consultado el 07 de enero de 2013], p. 8. 
indudable que la competencia que esta ley le otorga a la Corte Suprema para conocer y resolver los recursos de casación en el fondo, apunta exactamente a crear mecanismos tendientes a dar eficacia al principio de que la justicia debe ser cumplida. Como ya se dijo, la Corte Suprema es la garante de que la ley sea igual para todos, y requerida para que se pronuncie sobre si ello es efectivo, no puede excusarse de resolver a pretexto de que el fallo carece de relevancia jurídica para la adecuada interpretación y aplicación del derecho".

La Reforma del año 1995 pretendía algunas innovaciones a la casación, en especial al artículo 782 inciso segundo de ese Código, entre las que cabía considerar una posibilidad de desestimación previa a la vista de la causa de naturaleza diversa a la inadmisibilidad por razones formales, o al rechazo por manifiesta falta de fundamento, que consistía en carecer el asunto de la novedad e interés suficiente como para justificar la intervención de la Corte Suprema. Algo parecido al certiorati anglosajón. Tal posibilidad fue rechazada por el Tribunal Constitucional de manera categórica, pues, como se argumenta en el motivo $15^{\circ}$ de ese fallo,

“... de la manera en que se otorga esta facultad, se restringe el recurso de casación de fondo a los casos en que la infracción de ley con influencia en lo dispositivo del fallo sirva para generar doctrinas o jurisprudencia, funciones residuales de la sentencia y ajenas a su propio deber, cual es, el de resolver en derecho los conflictos sometidos a su decisión".

De manera categórica, los sentenciadores constitucionales manifiestan que la Carta Fundamental “

...básicamente reserva a una ley orgánica constitucional determinar las atribuciones de los tribunales necesarios para la pronta y cumplida administración de justicia y, por ello, no cumple con ese mandato este precepto que para lograr tal finalidad señala de manera indeterminada la carencia de una relevancia jurídica que no se precisa y que aparece vaga en su contenido y, en todo caso, desmedida en su alcance relativo a la interpretación y aplicación de la ley.

El tribunal de casación, encargado de vigilar el cumplimiento de los principios de igualdad ante la ley y de legalidad, no puede, sin vulnerar el cumplimiento de su deber, rechazar un recurso porque no tiene relevancia jurídica extraña a la materia de la litis. El objetivo de la casación es la aplicación de la ley en la solución de los conflictos y, residualmente, lograr una aplicación e interpretación uniforme de derecho"."

4.5 Por su parte, los profesores Jordi Delgado y L. Iván Díaz sintetizan en cuatro los principales problemas asociados a la unificación de jurisprudencia pretendida por el recurso extraordinario, ${ }^{15}$ a saber:

\footnotetext{
$14 \quad$ Ibidem, p. 5.

15 DELGADO, Jordi y DÍAZ, L. Iván, Op. cit., p. 285.
} 
4.5.1).- La concepción prevaleciente sobre el efecto relativo de las sentencias. Según los autores citados, existe un elevado consenso en la doctrina chilena más tradicional respecto del modo en que se debe entender el artículo $3^{\circ}$, inciso segundo, del Código Civil. En él se consagraría la relatividad de las sentencias, incluida por cierto las de la Corte Suprema, en el sentido que aquellas no pueden producir efecto más allá de los intervinientes en el respectivo juicio, con las excepciones señaladas.

Esta concepción constituye un primer problema para el cumplimiento de los objetivos del recurso extraordinario, ya que se pretende que las sentencias de la Corte Suprema, en particular las interpretaciones contenidas en aquellas, sean seguidas por el resto de los tribunales que integran el Poder Judicial. En otras palabras, se pretende que las decisiones interpretativas de la Corte Suprema tengan efectos más allá de las partes de la causa en que se han pronunciado. Contraponiéndose a la forma en que se entienden las decisiones judiciales y al modo en que los operadores jurídicos históricamente se han comportado frente a ellas a la luz del artículo $3^{\circ}$ del Código Civil.

4.5.2).- Falta de una cultura judicial tendiente a respetar las interpretaciones de la Corte Suprema. En este sentido citan lo acaecido con el recurso de unificación de jurisprudencia laboral y esto se debe a que ambos recursos presentan coincidencia en sus fines y en sus causales de procedencia.

La evidencia empírica muestra que el recurso de unificación de jurisprudencia laboral no ha cumplido sus objetivos respecto del resto del Poder Judicial. La Corte Suprema ha tendido a uniformar su jurisprudencia en diversas materias del ámbito laboral, pese a ello, en muchos casos las Cortes de Apelaciones no han prestado atención a las interpretaciones sostenidas en las sentencias de unificación.

Sin embargo, agregan los autores, que se podría pensar que es la falta de raigambre de la institución la que determina una ausencia de costumbre judicial. Es decir, las Cortes de Apelaciones no están, todavía, interiorizadas en su desempeño cotidiano con la observancia de la doctrina unificada. No obstante, toman de ejemplo el recurso de casación para unificación de doctrina en el proceso laboral español el que con más de veinte años nos muestra el mismo fenómeno.

En consecuencia, según los autores citados, todo esto muestra que no existe una cultura judicial tendiente a respetar las interpretaciones contenidas en las decisiones pronunciadas por la Corte Suprema en unificación de jurisprudencia. La consecuencia es un potente golpe en contra del cumplimiento de los objetivos de dicho recurso. Y, por lo mismo, un obstáculo al logro de varias de las ventajas asociadas a la existencia del mismo y que fueran más arriba reseñadas.

4.5.3).- Rechazo doctrinario a la idea de unificar la jurisprudencia. Fundamentado en diversas premisas, tales como: 
4.5.3.1.- La falta de independencia judicial. Es decir, el sometimiento a las interpretaciones de la Corte Suprema atenta contra la independencia con que deben contar los tribunales inferiores para resolver los casos entregados a su decisión.

4.5.3.2.- La petrificación del Derecho. La unificación de jurisprudencia se refiere a que impide la evolución del Derecho. De acuerdo con esta perspectiva, dicha sumisión petrifica o rigidiza el ordenamiento jurídico.

4.5.3.3.- El impredecible juicio de igualdad. Consiste en la imposibilidad de contar con unívocos juicios de igualdad. En efecto, la unificación de jurisprudencia es una aplicación del mandato trata igual a lo igual y desigual a lo desigual, específicamente en el ámbito jurisdiccional. Sin embargo, para poder aplicarlo, frente a cada caso sería necesario determinar si sus hechos coinciden con los hechos de un caso anteriormente resuelto por la Corte Suprema, pues solo así se sabría si se trata de casos iguales o desiguales.

De este modo, podría ocurrir que la Corte Suprema entienda que no son relevantes las diferencias que puedan existir entre los casos y persiga la unidad de la interpretación en las normas ante supuestos desiguales. O bien pudiera ser que confundiera igualdad con identidad, de modo que llevase al recurso a resultar además de extraordinario, excepcional. Cualquiera de las dos situaciones es posible debido a que, como se sabe, el concepto de igualdad es esencialmente valorativo y la valoración debe ser realizada por el juzgador.

4.5.3.4.- ¿Búsqueda de la igualdad en la aplicación de la ley? En atención, especialmente, a las causales del recurso afirman los autores, que esta pretendida defensa del derecho fundamental a la igualdad no es, en realidad, la última finalidad que persigue el legislador. El recurso tiene por objetivo cierto la búsqueda de una jurisprudencia uniforme, hecho que incidirá en la consecución de la igualdad en la aplicación de la ley, pero el legislador no contempló expresamente esta previsión en el texto legal. Además, en la práctica podremos ver como la jurisprudencia podrá ser igual, pero no necesariamente se van a establecer las distinciones necesarias que cada caso particular merezca.

4.5.3.5.- Seguridad jurídica restringida. No todos los casos llegarán a conocimiento de la Corte Suprema, debido a las restricciones que se han diseñado al efecto. Esto también redundará en una menor consecución de la aplicación de los principios de igualdad y seguridad jurídica.

En efecto, la Corte Suprema, según la prescripción normativa, cumple con seleccionar aquellos supuestos que, cumpliendo con todos los requisitos, presentan interés público. Pues bien, será muy difícil que un caso en que se discute Derecho privado alcance relevancia pública, de modo que la seguridad jurídica se va a ver comprometida, desde el momento en que la Corte comience a funcionar con una lógica economicista en la selección de sus asuntos. El (ab)uso de una potestad 
discrecional de selección de asuntos puede orientar la actuación de la Corte Suprema hacía la consecución de unos datos estadísticos engañosos en que consigue índices de resolución muy rápidos, en base a la inadmisión sistemática de todo tipo de asuntos.

El problema concreto al hablar de la selección discrecional de asuntos es, precisamente, el poder que se le otorga al órgano jurisdiccional y sus lindes respecto a lo que se pueda considerar arbitrariedad.

4.5.3.6.- El quiebre del sistema de fuentes de la familia europeo-continental. Al respecto, afirman que, empíricamente hablando, en dicho entorno jurídico cultural se rechaza otorgar a la jurisprudencia el carácter de fuente del Derecho. La adopción de esta perspectiva puede tener justificaciones ideológicas o simplemente culturales. Así, y desde un plano ideológico, admitir que las decisiones judiciales tienen fuerza normativa provocaría la confusión de funciones del Estado y, según sostiene algún autor, incluso conllevaría la destrucción del estado de Derecho. Desde una perspectiva cultural, muchos juristas se niegan a abandonar la concepción tradicional del juez como mero aplicador del Derecho.

4.5.4).- El problema de la función de la Corte Suprema. Parece posible sostener que la función del máximo intérprete pasa por algo más allá que uniformar jurisprudencia (que también es una de sus misiones). Junto con ello, su función ha de ser defender la correcta aplicación de la ley, coincidiendo con la misión del recurso de casación en el fondo que, históricamente, determinó la creación de un tribunal con vocación de mantener y cuidar la observancia de la ley.

\section{Conclusiones}

A raíz de todo lo expresado en este breve trabajo, para concluir, debemos preguntarnos si resulta necesaria la implementación del recurso extraordinario, en atención a la carga de trabajo que presenta actualmente nuestro Máximo Tribunal. Claramente, la respuesta a dicha interrogante según la evidencia empírica y los datos aportados por la Fundación Jaime Guzmán, nos demuestran que con el certiorari no precisamente se va a producir una reducción sistemática de los casos o asuntos, al contrario, en la práctica se daría la situación que igualmente se recurriría ante la Excma. Corte, por cuanto, el derecho al recurso forma parte del debido proceso y, como tal, la mayoría de los letrados tienen la facultad de al menos intentar dejar sin efecto una resolución. Por esta razón, no se va a disminuir el hecho que los abogados sigan presentando recursos, aún cuando sepan que no obtendrán resultados satisfactorios, esto es parte de la mala costumbre de "justificar los honorarios cobrados".

Además, debemos tener en consideración lo ocurrido en el país trasandino, la realidad demuestra que el número de ingresos no se reduce con el certiorari, 
al contrario, se mantiene y aumenta. En razón de lo anterior, existen fundados argumentos para criticar o no aceptar la implementación del tan bullado certiorari en nuestro ordenamiento procesal. Además, debemos señalar que la realidad comparada dista mucho de lo que acontece en un país pequeño como el nuestro, por lo que aparece justificable en ámbito internacional, no se acerca ni justifica su ejecución en ámbito local.

Ahora bien, tal como señaláramos en una publicación ${ }^{16}$, para implementar un nuevo sistema procesal no es necesario ser tan radical y abolir completamente el sistema imperante, es más, resulta completamente útil rescatar lo positivo del sistema vigente y mejorarlo, así se construye sobre cimientos sólidos. No se trata de rechazar la implementación tendencias modernas o de negarse a las técnicas que han resultado efectivas en el derecho comparado, al contrario, se trata de mejorar el sistema en base a lo empírico y, en lo posible, adecuar dichas tendencias a nuestra tradición jurídica nacional, respetando -ciertamente- los principios que inspiran la reforma procesal civil.

Por otro lado, respecto de la aplicación del certiorari, no debemos olvidar que la razón histórica del establecimiento de la discrecionalidad de la revisión de recursos, al menos en el caso de los Estados Unidos de América, fue el optimizar la carga de trabajo de la Suprema Corte. Pero no nos olvidemos, por una parte, que en Estados Unidos el sistema judicial estatal (no federal) absorbe la gran mayoría de los casos que se presentan en ese país en materia civil, criminal, laboral y de familia, el que cuenta en la mayoría de los estados con sus respectivos tribunales de primera instancia, Cortes de Apelaciones y Corte Suprema (o equivalentes), por lo que las partes ya han tenido en la mayoría de los casos que los afectan todas esas instancias o niveles de revisión de sus causas; y por otra, tampoco nos olvidemos que en ese país no existe una Corte constitucional como nuestro Tribunal Constitucional, sino que ese papel lo cumple la misma Suprema Corte de Estados Unidos ${ }^{17}$.

En este entendido, las diferencias con nuestro sistema en cuanto al rol de la Corte Suprema son, entonces, relevantes. Creemos que nosotros podemos buscar formas menos gravosas para optimizar la función de nuestra Corte Suprema, sin perder nada a cambio de no adoptar el modelo discrecional, tal como se hizo en material penal y laboral. Dicho sea de paso, de no hacerse así se produciría una desigualdad ante la ley para los litigantes civiles respecto del acceso a la Corte Suprema ${ }^{18}$.

16 Vid. AVENDAÑO, Ignacio, "El principio de congruencia. Su regulación en el proceso civil actual y en el proyecto de ley del CPC", disponible en: http://www.lexweb.cl/el-principiode-congruencia-su-regulacion-en-el-proceso-civil-actual-y-en-el-proyecto-de-ley-del-cp [Consultado el 09 de enero de 2013].

17 Vid. DEL RÍO, Gabriel, "Lo que va de reforma", disponible en: http://diario30.com/judicial/loque-va-de-reforma/ [Consultado el 13 de enero 2013].

18 Ibídem. 